Volume 1 No. 1

Februari 2020

e-ISSN : 2721-9062

Website:

jurnal.umj.ac.id/index.php/JMMB

Email : immb.febumj@gmail.com

jmmb@umj.ac.id

\title{
ANALISIS DAMPAK PENGOPERASIAN MASS RAPID TRANSIT (MRT) TERHADAP PENJUALAN PRODUK DAN KEPUTUSAN PEMBELIAN KONSUMEN
}

\author{
Fajar Adi Prakoso ${ }^{*}$, Sampor $\mathrm{Ali}^{2}$ \\ ${ }^{1,2}$ Jurusan Manajemen, Fakultas Ekonomi dan Bisnis, Universitas Muhammadiyah Jakarta, Jl. KH. Ahmad \\ Dahlan, Jakarta, 15419 \\ *f.adiprakoso@umj.ac.id
}

Diterima: 4 Februari 2020

DOI : 10.24853/jmmb.1.1.25-30

Direvisi: 9 Februari 2020

Disetujui: 12 Februari 2020

\begin{abstract}
ABSTRAK
Penelitian bertujuan Untuk mengetahui dampak Pengoperasian Mass Rapid Transit terhadap penjualan produk dan keputusan pembelian di Points Square Lebak Bulus, Jakarta. Penelitian ini menggunakan jenis penelitian campuran dengan pendekatan kuantitatif dan kualitatif (Mix Method). Variabel yang digunakan dalam penelitian yaitu Pengoperasian MRT, Penjualan produk dan Keputusan pembelian konsumen.Sampel yang digunakan dalam penelitian ini berjumlah 100 orang responden.Teknik pengambilan sampel yang digunakan adalah simple random sampling. Analisis data yang digunakan adalah analisis deskriptif dengan menggunakan strategi triangulasi konkuren. Dalam strategi ini, peneliti mengumpulkan data kualitatif dan data kuantitatif dalam waktu yang bersamaan. Hasil penelitian menunjukkan bahwa Pengoperasian MRT tidak berdampak terhadap penjualan produk dan Keputusan konsumen untuk membeli diPoints Square Lebak Bulus, Jakarta Selatan.
\end{abstract}

Kata kunci: Pengoperasian MRT, Penjualan Produk,Keputusan Pembelian Konsumen

\begin{abstract}
This research aims to determine the impact of the operation of Mass Rapid Transit on product sales and purchasing decisions at Points Square Lebak Bulus, Jakarta. This research uses a mixed type of research with quantitative and qualitative approaches (Mix Method). The variables used in this research are MRT operation, product sales, and consumer purchasing decisions. The samples used in this study were 100 respondents. The sampling technique used was simple random sampling. Analysis of the data used is descriptive analysis using concurrent triangulation strategies. In this strategy, researchers collect qualitative and quantitative data at the same time. The results showed that the operation of the MRT had no impact on product sales and consumers' decision to buy at Points Square Lebak Bulus, South Jakarta.
\end{abstract}

Keywords: MRT operations, product sales, consumer purchasing decisions 


\section{PENDAHULUAN}

Pemerintah saat ini memprioritaskan infrastruktur sebagai bagian dari fokus utama dalam pembangunan ekonomi. Dengan pertumbuhan ekonomi dikisaran $5 \%$ pemerintah ingin agar konektivitas, pemerataan ekonomi serta menciptakan pusat ekonomi baru diberbagai daerah. Pertumbuhan dan perkembangan suatu negara terjadi bila pembangunan dapat dilakukan secara berkesinambungan oleh segenap elemen bangsa dalam memajukan ekonomi baik dikota-kota besar di Indonesia maupun di daerah.

Jakarta saat ini sebagai ibu kota Negara, pusat kegiatan pemerintahan, ekonomi, dan bisnis memiliki peran yang besar dalam memajukan ekonomi negara mengingat hampir lebih dari $50 \%$ perputaran ekonomi negara ini ada diJakarta. Disisi lain masalah kemacetan merupakan hal sudah biasa terjadi di Jakarta dan belum terselesaikan sampai saat ini. Dengan mobilitas penduduknya yang tinggi baik yang ada di Jakarta maupun warga sekitar penyangga Jakarta yang bekerja di Jakarta seperti Bogor,Depok, Tangerang dan Bekasi menuntut adanya sarana prasarana yang baik terutama moda transportasi masa yang besar, dimana dapat mengangkut dengan kapasitas yang banyak, namun cepat serta ramah lingkungan.

Pada tanggal 17 Juni 2008 PT Mass Rapid Transit Jakarta (PT MRT Jakarta) dibentuk oleh pemda DKI yang berbadan hukum Perseroan Terbatas dengan saham mayoritas dimiliki oleh pemda DKI. Dengan beroperasinya MRT yang berpusat diLebak Bulus, Jakarta Selatan sekaligus sebagai Depo maka akan berdampak terhadap kegiatan ekonomi disekitar kawasan tersebut.

Salah satunya pusat perbelanjaan Points Square lebak bulus yang letaknya dekat dengan stasiun MRT lebak bulus. Points Square telah beroperasi sejak tahun 2005 dengan luas 2,5 Hektare. Sebelum MRT beroperasi dan masih dalam tahap pembangunan beberapa pelaku usaha diPoints Square mengeluh dengan sepinya pembeli. Akses jalan yang sulit saat pembangunan MRT diduga salah satu penyebab konsumen enggan membeli di Points Square. Hal tersebut tentunya berbanding terbalik dengan lokasi Poins Square yang strategis dan dilewati jalur MRT yang memiliki potensi bisnis yang cukup menjanjikan.

Dengan Mobilitas masyarakat yang tinggi menggunakan transportasi mendorong Perubahan-perubahan pula pada kebutuhan masyarakat untuk berbelanja.

Hal tersebut dapat diakibatkan adanya perubahan gaya hidup (life style) masyarakat sehingga menuntut kenyamanan dan kemudahan dalam pemenuhan kebutuhannya Hal tersebut berpengaruh terhadap pelayanan dan kepuasaan dalam berbelanja. (Setyawarman, Adityo:2009). Para pelaku usaha mengharapkan dengan penjualan yang meningkat diimbangi dengan sikap konsumen yang melakukan pembelian, karena semakin besar konsumen membeli produk mereka maka akan semakin besar pula peluang pelaku usaha memperoleh keuntungan. Konsumen pun memiliki pilihan yang beragam dalam memutuskan untuk membeli produknya.

Pembeli saat ini telah memiliki banyak pilihan dalam membeli suatu produk dengan beragamnya produk dipasaran berbagai alternatif produk dapat dipilih untuk kemudian memutuskan untuk melakukan pembelian. Pertimbangan dan perbandingan antara satu produk dengan yang lainnya turut menjadi perhatian konsumen, mengingat persaingan yang kompetitif antar penjual

\section{METODE PENELITIAN}

Dalam penelitian ini populasi didapat dari orang yang berkunjung ke points square lebak bulus .Dengan menggunakan Simpel Random Sampling dimana populasi diambil secara acak dimana setiap anggota populasi dapat memiliki kesempatan yang sama untuk terpilih menjadi sampel. Malhotra (2010) memberikan panduan ukuran sampel yang diambil dapat ditentukan dengan cara mengalikan jumlah variabel dengan 5, atau 5x jumlah variabel.

Dengan demikian jika jumlah variabel yang diamati berjumlah 20, maka sampel minimalnya adalah 5 x $20=100$.

Maka dalam penelitian ini sampel yang digunakan sebanyak 100 responden. Dalam penelitian ini wawancara dilakukan kepada penjual maupun pembeli yang berada di Points Square, untuk mengetahui keterkaitan hubungan tiap variabel dan sebagai informasi dalam mengisi kuesioner penelitian.

Dalam penelitian ini observasi dilakukan dengan cara mempelajari dan mengadakan 
pengamatan secara langsung ke Points Square untuk mendapatkan bukti-bukti yang dapat mendukung dan melengkapi hasil penelitian. Dalam penelitian ini studi kepustakaan diambil dari buku, jurnal, website yang mendukung. Dalam penelitian ini menggunakan analisis statistik deskriptif. Data tersebut berasal dari data kuantitatif dan kualitatif.

Data yang telah diperoleh selanjutnya di analisa untuk menjawab rumusan masalah. dalam penelitian ini menggunakan Strategi triangulasi konkuren. Dalam strategi ini, peneliti mengumpulkan data kualitatif dan data kuantitatif dalam waktu yang bersamaan pada tahap penelitian, kemudian membandingkan antara data kualitatif dengan data kuantitatif untuk mengetahui perbedaan dan kombinasi.

\section{HASIL DAN PEMBAHASAN}

Tabel 1. Produk Usaha

\begin{tabular}{|c|c|c|c|c|c|}
\hline \multirow{3}{*}{ NO } & \multirow{3}{*}{ Produk Usaha } & \multicolumn{4}{|c|}{ Points Square Lebak Bulus } \\
\hline & & \multicolumn{2}{|c|}{ Sebelum MRT } & \multicolumn{2}{|c|}{ Sesudah MRT } \\
\hline & & Angka & Prosentase & Angka & Prosentase \\
\hline 1 & Handphone & 33 & $33 \%$ & 20 & $20 \%$ \\
\hline 2 & Komputer & 41 & $41 \%$ & 30 & $30 \%$ \\
\hline 3 & Pakaian & 13 & $13 \%$ & 9 & $9 \%$ \\
\hline 4 & Makanan dan Minuman & 11 & $11 \%$ & 39 & $31 \%$ \\
\hline & Total & 100 & $100 \%$ & 100 & $100 \%$ \\
\hline
\end{tabular}

Berdasarkan Tabel 1 diketahui jenis usaha yang terdapat di Points Square sebelum MRT beroperasi dari 100 Responden, paling banyak berjualan Handphone dengan 41 Responden atau dengan prosentase $41 \%$ dan paling sedikit yakni berjualan makanan dan minuman dengan 11 responden atau $11 \%$. Sedangkan setelah MRT beroperasi paling banyak berjualan makanan dan minuman dengan 39 Responden atau dengan prosentase $39 \%$ dan paling sedikit yakni berjualan Pakaian dengan 9 responden atau $9 \%$.

Tabel 2. Pendapatan Penjual

\begin{tabular}{|c|c|c|c|c|c|}
\hline \multirow{3}{*}{ NO } & \multirow{3}{*}{ Pendapatan Penjual } & \multicolumn{4}{|c|}{ Points Square Lebak Bulus } \\
\hline & & \multicolumn{2}{|c|}{ Sebelum MRT } & \multicolumn{2}{|c|}{ Sesudah MRT } \\
\hline & & Angka & Prosentase & Angka & Prosentase \\
\hline 1 & $<$ Rp. 5.000 .000 & 21 & $21 \%$ & 53 & $53 \%$ \\
\hline 2 & Rp. 5.000 .000 - Rp. 10.000 .000 & 26 & $26 \%$ & 21 & $21 \%$ \\
\hline 3 & Rp. 10.000 .000 - Rp. 20.000 .000 & 33 & $33 \%$ & 13 & $13 \%$ \\
\hline 4 & > Rp. 20.000 .000 & 20 & $20 \%$ & 13 & $13 \%$ \\
\hline & TOTAL & 100 & $100 \%$ & 100 & $100 \%$ \\
\hline
\end{tabular}

Berdasarkan Tabel 2 diketahui pendapatan penjual di Points Square sebelum MRT beroperasi dari 100 Responden, paling banyak berpenghasilan Rp. 10.000 .000 - Rp. 20.000.000 dengan 33 Responden atau dengan prosentase $33 \%$ dan paling sedikit berpenghasilan > Rp. 20.000 .000 dengan 20 responden atau 20\%. Sedangkan setelah MRT beroperasi paling banyak berpenghasilan $<\mathrm{Rp}$. 5.000.000 dengan 53 Responden atau dengan prosentase $53 \%$ dan paling sedikit berpenghasilan Rp. 10.000.000- Rp. 20.000.000 dan > Rp. 20.000.000 dengan masing-masing 13 responden atau $13 \%$.

Tabel 3. Frekuensi Kedatangan Konsumen

\begin{tabular}{|c|c|c|c|c|c}
\hline \multirow{2}{*}{ NO } & \multirow{2}{*}{$\begin{array}{c}\text { Frekuensi Kedatangan } \\
\text { Konsumen }\end{array}$} & \multicolumn{4}{|c}{ Points Square Lebak Bulus } \\
\cline { 3 - 6 } & & \multicolumn{2}{|c|}{ Sebelum MRT } & \multicolumn{2}{c}{ Sebelum MRT } \\
\cline { 3 - 6 } & Angka & Angka & Angka & Angka \\
\hline 1 & $<5$ Kali & 5 & $5 \%$ & 59 & $59 \%$ \\
\hline 2 & 5 Kali-10 Kali & 28 & $28 \%$ & 9 & $9 \%$ \\
\hline 3 & 11 Kali- 20 Kali & 57 & $57 \%$ & 11 & $11 \%$ \\
\hline 4 & $>20$ Kali & 10 & $10 \%$ & 21 & $21 \%$ \\
\hline \multicolumn{2}{r}{} & 100 & $100 \%$ & 100 & $100 \%$ \\
\hline
\end{tabular}

Berdasarkan Tabel 3 diketahui frekuensi kedatangan konsumen ke Points Square sebelum MRT beroperasi dari 100 Responden, paling sering konsumen ke Points Square sebanyak 11 kali - 20 kali dengan 57 Responden atau dengan prosentase 57\% dan paling sedikit datang sebanyak $<5$ Kali dengan 5 responden atau 5\%. Sedangkan setelah MRT beroperasi paling sering konsumen ke Points Square sebanyak 59 Responden atau 59\% responden dan paling sedikit datang sebanyak 5 Kali - 10 Kali dengan 9 responden atau dengan prosentase $9 \%$.

Tabel 4. Alasan Konsumen Membeli

\begin{tabular}{|c|c|c|c|c|c}
\hline \multirow{2}{*}{ NO } & \multirow{2}{*}{$\begin{array}{c}\text { Alasan Konsumen } \\
\text { Membeli Di Points } \\
\end{array}$} & Square & \multicolumn{4}{|c}{ Points Square Lebak Bulus } \\
\cline { 3 - 6 } & Sebelum MRT & \multicolumn{2}{c}{ Sebelum MRT } \\
\hline 1 & Produk Beragam & 31 & $31 \%$ & 27 & $27 \%$ \\
\hline 2 & Harga Terjangkau & 21 & $21 \%$ & 13 & $13 \%$ \\
\hline 3 & Banyak Promosi,Diskon & 35 & $35 \%$ & 12 & $12 \%$ \\
\hline 4 & Lokasi Strategis & 13 & $13 \%$ & 52 & $52 \%$ \\
\hline \multicolumn{7}{c}{ TOTAL } & 100 & $100 \%$ & 100 & $100 \%$ \\
\hline
\end{tabular}

Berdasarkan Tabel 4 diketahui alasan konsumen membeli di Points Square sebelum MRT beroperasi adalah karena banyak promosi, diskon sebanyak 35 Responden atau $35 \%$ dan jumlah terkecil sebanyak 13 responden atau $13 \%$ yang beralasan ke Points Square karena lokasinya strategis. Sedangkan setelah MRT beroperasi sebanyak 52 responden atau $52 \%$ beralasan karena Points Square lokasinya strategis dan yang terkecil sebanyak 12 responden atau $12 \%$ beralasan mereka mau membeli di Points Square karena banyak promosi,diskon.mereka mau membeli di Points Square karena banyak promosi,diskon. 


\section{KESIMPULAN}

Berdasarkan hasil penelitian dan pembahasan diatas maka dapat disimpulkan bahwa, pengoperasian MRT tidak berdampak terhadap penjualan produk dan dari segi kuantitas penjualan mengalami penurunan, hal ini terlihat dari pendapatan yang diperoleh penjual sesudah MRT beroperasi hanya memperoleh < Rp 5.000.000 dengan 53 responden atau dengan prosentase sebesar 53\% dengan produk makanan dan minuman sebagai penyumbang terbesar dengan prosentase sebesar 39\%. Sementara itu sebelum MRT beroperasi pendapatan yang diraih penjual bisa mencapai Rp. 10.000.000-Rp. 20.000.000 dengan 33 responden atau dengan prosentase sebesar $33 \%$ dengan produk komputer sebagai penyumbang terbesar dengan prosentase sebesar $41 \%$. Pengoperasian MRT tidak berdampak terhadap keputusan konsumen untuk membeli di Points Square serta dari kuantitas kedatangan konsumen mengalami penurunan, hal ini terlihat dari frekuensi kedatangan konsumen sesudah MRT beroperasi hanya < 5 Kali dengan 59 responden atau dengan prosentase sebesar 59\% dengan alasan konsumen karena lokasinya strategis dengan 52 responden atau dengan prosentase 52\%, Sementara itu sebelum MRT beroperasi frekuensi kedatangan konsumen 11 kali - 20 kali dengan 57 responden atau dengan prosentase sebesar 57\%. Dengan alasan konsumen karena banyak promosi, diskon dengan 35 responden atau $35 \%$.

Penurunan penjualan lebih disebabkan pergeseran pembelian konsumen akan suatu produk dari komputer atau barang elektronik ke produk makanan dan minuman. Hal ini bisa dikarenakan pengaruh dari harga atau karena berubahnya budaya konsumen yang cenderung senang berkumpul ditempat makan atau restoran. Peneliti menyarankan dengan beroperasinya MRT dapat lebih dimanfaatkan pengelola Points Square bekerjasama dengan pengelola MRT menyediakan akses langsung yang mudah kepada penumpang MRT ke points square baik melalui tangga jalan,jembatan maupun sejenisnya agar dapat meningkatkan penjualan. Berdasarkan Penelitian diatas sesudah pengoperasian MRT, peneliti menemukan bahwa responden menyatakan faktor lokasi yang strategis sebagai alasan untuk melakukan pembelian di Points Square namun frekuensi kedatangannya hanya $<5$ kali. Hal ini mengindikasikan bahwa faktor lokasi strategis saat ini tidak menjamin suatu usaha akan laku atau menguntungkan. Peneliti menyarankan dengan lokasi yang strategis tersebut dapat lebih dimaksimalkan dengan strategi pemasaran yang tepat seperti promosi,diskon lain sebagainya serta memanfaatkan penjualan online sehingga tidak hanya mengandalkan faktor lokasi saja.

\section{DAFTAR PUSTAKA}

Abdullah, Thamrin dan Francis Tantri. 2012. Manajemen Pemasaran. Depok: PT Raja Grafindo Persada

Basu Swastha, DH dan Irawan. 1990. Manajemen Pemasaran Modern. Yogyakarta: Liberty.

Creswell John.W. 2014. Penelitian Kualitatif \& Desain Riset. Yogyakarta: Pustaka Pelajar.

Creswell Jhon.W, Research Design:Pendekatan Kualitatif, Kuantitatif, dan Mixed, Terj.Dari Research Design: Qualitative, Quantitative, and Mixed Methods Approaches. Third Edition

Hasan, A. (2011). Marketing. Yogyakarta: Media Utama.

Kotler, Amstrong. 2001. Prinsip-prinsip pemasaran, Edisi keduabelas, Jilid 1. Jakarta: Erlangga

Kotler, Philip dan Amstrong, Gary. 2016. Principles Of Marketing. Global Edition, Pearson Education, Harlow.

Malhotra Naresh K, 2010. Marketing Research and Applied Orientation Sixth Edition Pearson Education.

Nazir.2014. Metode Penelitian. Bogor. Ghalia Indonesia

Setyawarman, Adityo. Pola Sebaran Dan Faktor - Faktor Yang Mempengaruhi Pemilihan Lokasi Retail Modern (Studi Kasus Kota Surakarta), Thesis Program Studi Magister Teknik Pembangunan Wilayah Dan Kota Universitas Diponogoro. Semarang (2009)

Sugiyono. (2016). Metode Penelitian Kuantitatif, Kualitatif dan R\&D. Bandung: PT Alfabet.

Sukardi. 2015. Metodologi Penelitian Pendidikan. Jakarta : PT Bumi Aksara

Supriyati. 2011. Metodologi Penelitian.Bandung: Labkat press. 
Fajar Adi P, Sampor Ali : Analisis Dampak Pengoperasian Mass Rapid Transit (Mrt) Terhadap Penjualan Produk Dan Keputusan Pembelian Konsumen.

Jurnal Muhammadiyah Manajemen Bisnis 1 (1) pp 23-27 ㄷ 2020

Sutisna, Sunyoto. (2013). Perilaku Konsumen dan Komunikasi Pemasaran. Jakarta: PT. Remaja Rosdakarya.

https://www.jakartamrt.co.id Diakses Pada Tanggal 4 Oktober 2019

(https://www.tagar.id/negara-pertama-didunia-yang-menggunakan-mrt). Diakses Pada Tanggal 17 Oktober 2019

http://poinsquare.com/ Diakses Pada Tanggal 29 Oktober 2019 